\title{
EARLY IDENTIFICATION OF FOOT ULCER USING THERMAL FOOT IMAGE
}

\author{
A Bhargavi Haripriya, Assistant Professor ; Dr. M Anburajan, Professor \& Head \\ Department of Biomedical Engineering, SRM University, Kattankulathur \\ bhargavi.a@ktr.srmuniv.ac.in, anburajan.m@ktr.srmuniv.ac.in
}

According to WHO statistics Diabetes has affected about $9 \%$ of the world population who are above 18 years. With out proper health care and awareness, this disease tends to reduce the functionality of various systems in the body. As Diabetes effects immune system, it becomes very difficult to cure any ailment if it is diagnosed during later stages. About $15 \%$ of diabetic people tend to develop foot ulcers , more than $40 \%$ of the ulcers lead to limb amputation. Early diagnosis of foot ulcer can reduce the need for limb amputation to a great extent.

Conventional methods like tuning fork method, need experts to identify ulcer. Thermal imaging is a non invasive method of imaging the infrared (IR) radiation emitted by the body. The aim of the project is to capture thermal foot images and identify foot ulcer at early stages, through computerization. The work is done on gray scale image. The background of the image has to be eliminated through intensity slicing. Through cropping left and right foot are obtained as separate image. Left foot is later mirror and fused with the right foot. The fusion of the images have to be done with the help of watershed method. If the temperature of the same area of the foot varies by more that 2 degree centigrade the possibility of ulceration is high.

Currently the work is in the basic stage. The final result will be a completely automated graphical user interface (GUI) where the technician with minimum expertise is able to operate.

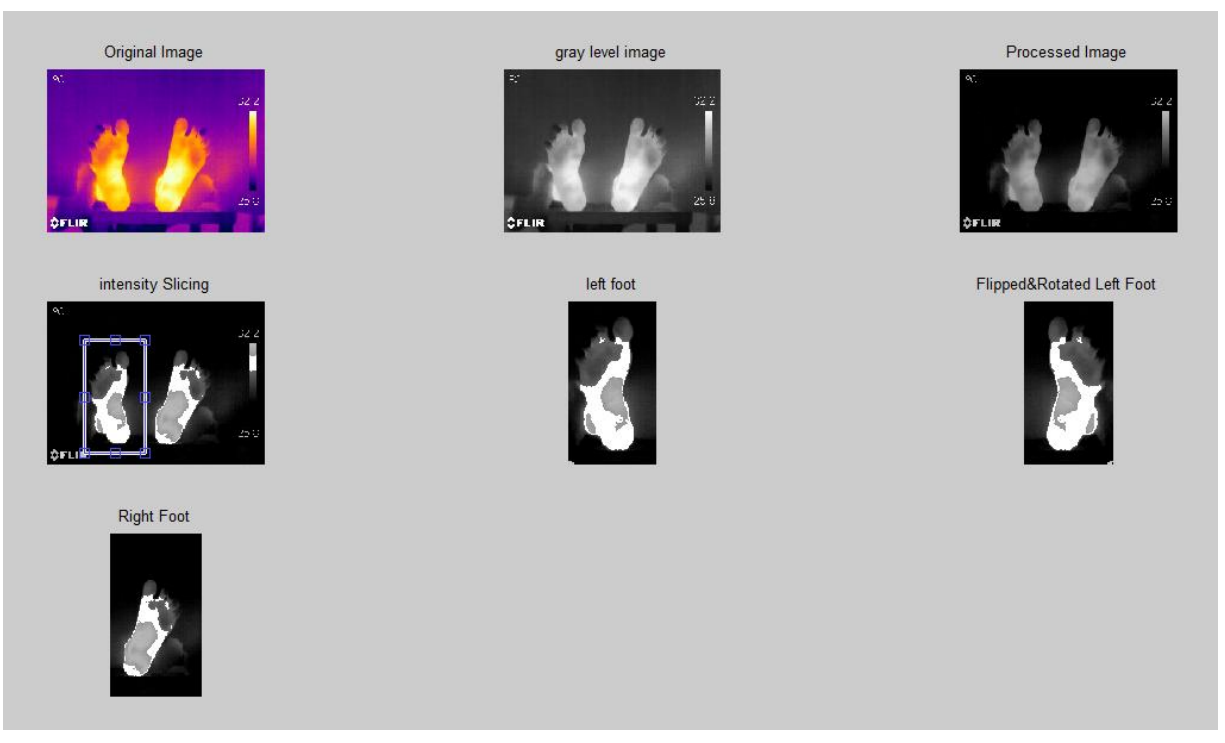

